\title{
Ecological Studies on the Biological Production of Young Amberfish Community in the Sendai Bay*1_-II Relationships between Food Chains and Fish Fauna
}

\author{
Akihiro OKATA*2 \\ (Received October 15, 1975)
}

\begin{abstract}
In order to obtain the distinctive features of fish fauna in typical areas of Sendai Bay, fuctuations in the amount of each species caught by set-nets have been investgiated. Comparing the species compositions between areas, the coast of Sendai Bay can be divided into four biological areas. These partitions help to understand the distributive patterns of benthic animals and the water mass in the Bay. This distributive phenomena suggests that there is close interspecies relationship in each of the growth stages of the fishes and are adaptationally connected to several conditions of the nonorganic environment.

In a period of temperature rise, many species of fish appear in each area followed by one after the other, and most of the main species are already in the areas by late August, when the water temperature begins to show a descending tendency. From the view point of the tendency for peaks in the amount of catch, at intervals of ten days, it was recognized that the peaks in catch at any one time is composed of not more than five species at the maximum, and generally two or more species, linked either with predator-prey relationships, and scarcely overlap with each other in a restricted space.

In addition to the amberfish (Seriola quinqueradiata) community, we can find many species of fish which prefer the anchovy to other foods, though the formation mechanism of communities is not always identical to that of the amberfish community. Species population show a dynamic life pattern corresponding to several growth stages peculiar to the species, and changes the state of distribution and aggregation. In such dynamic process of life, a species population is connected closely to other species populations owing to predator-prey relationships, and they form a biotic community. This paper deals with a phase of the community constructed by several populations that extend over a wide area. Picking up typical terminal species from fish fauna in the Sendai Bay, the types of community formation, as a part of the whole, have been classified into three classes; waiting type, sojourning type and passing type. These three types of community have the common feature in a point that they include the anchovy as a principal member in a community. However, it is reasonable to consider the main part of the community as separate from other communities in time and space, and that two or more communities rarely hold a common school of the same anchovy population, but connect some definite school of fish.
\end{abstract}

In the previous paper, ${ }^{1 /}$ the author gave a definition of community as a biotic group that constitutes the production system recognizable through the predator-prey relationships, and it has been realized that carnivorous fishes more or less take the anchovy (Engraulis japonica) for food in the Sendai Bay.

A basic unit, constructing the community, is a species population, which shows dynamic life pattern corresponding to several growth stages peculiar to species, and changes the state of distribution and aggregation. Accordingly, the community, observed in such

*1 A part of the thesis work for Dr. of Agriculture from Tohoku University.

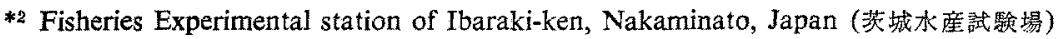


restricted area as the Sendai Bay, is regarded as a phase of the community that extends over more wide areas.

Because of the anchovy play an important role as food material for the production of fishes in high food niche, the fish is not only one of the important member of the amberfish community, but also of the other fish communities. Consequently, it may well be that there are some mechanisms coordinating the interference took place among two or more communities in connection with the anchovy.

The present report describes a general view of the pelagic fish fauna in the Sendai Bay and deals primarily with relation between the fauna and the food chains obtained in the preceding paper.

\section{Materials and Methods}

In an attempt to be well informed about the living condition and distribution of fishes that migrated in the coast of the Sendai Bay, records of daily catch by the set-nets were utilized. The records have been collected from typical five fishery grounds representing the coast of the Bay, namely, south-west area (A), the mouth part of the Matsushima bay $(B, C)$, the inner part of the Sendai Bay (D) and north-east part of the Sendai Bay (E),

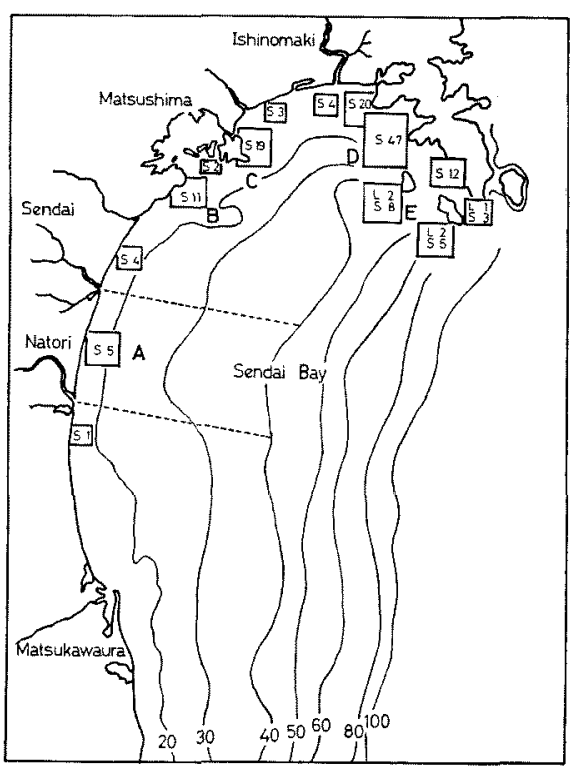

Fig. 1. Distribution of the set nets in the Sendai Bay, 1968. Signs and the numbers in the frame represent the size and number of fishing units operated (S: small sized set-net, L: large sized set net). as shown in Figure 1. The set-net in the area $\mathbf{E}$ is larger than the other in size and has been operated by an association. Each set-net is set up at the coast area shallower than 30 $m$ in depth. In the high zenith of fishing, the nets are hove up twice, but generally once per day.

\section{Result and Discussion}

\section{Coastal fish fauna in the Sendai}

Bay Looking over a transition of total amounts of catch of the setnets in the Sendai Bay, during the period from 1965 to '71, about from 4 to 5 thousands tons of fishes have been caught per year in an average, and kept stability as well as the fishing intensity (Table 1). 
Many species of organisms have been caught by the nets at the coastal fishing grounds as shown in Table 2, however, most of those can be included in a category what is called the coastal pelagic fishes, represented by such species as the mackerel (Pneumatophorus japonicus), the amberfish (Seriola quinqueradiata), the anchovy and so on.

According to the grade of amounts of total catch at five fishery grounds during the period from May to November, some typical species have been taken out and arranged in Table 3. Calculating weight percentage of each species to the total, we can find distinctly that the anchovy get the first $(25.7 \%)$, the mackerel the second $(24.1 \%)$ and the amberfish

Table 1. Number of fishing units operated, number of efforts and catches by type of the set nets in the Sendai Bay

\begin{tabular}{|c|c|c|c|c|c|c|c|c|}
\hline \multirow[b]{2}{*}{ Year } & \multicolumn{4}{|c|}{ Large sized } & \multicolumn{4}{|c|}{ Small sized } \\
\hline & $\begin{array}{l}\text { Number of } \\
\text { set nets }\end{array}$ & Effort & $\begin{array}{l}\text { Catch } \\
\text { (ton) }\end{array}$ & CPUE & $\begin{array}{l}\text { Number of } \\
\text { set nets }\end{array}$ & Effort & $\begin{array}{l}\text { Catch } \\
\text { (ton) }\end{array}$ & CPUE \\
\hline 1965 & 7 & 873 & 2,229 & 0.3648 & 144 & 19,908 & 721 & 0.00025 \\
\hline 1966 & 7 & 905 & 3,358 & 0.5301 & 134 & 18,602 & 2,324 & 0.00093 \\
\hline 1967 & 7 & 871 & 1,968 & 0.3228 & 154 & 19,252 & 2,277 & 0.00076 \\
\hline 1968 & 6 & 900 & 1,845 & 0.3417 & 144 & 19,119 & 1,796 & 0.00065 \\
\hline 1969 & 6 & - & 2,031 & - & 162 & - & 2,895 & - \\
\hline 1970 & 5 & 891 & 2,267 & 0.5089 & 172 & 24,023 & 2,042 & 0.00049 \\
\hline 1971 & 6 & - & 2,023 & - & 185 & - & 2,958 & - \\
\hline
\end{tabular}

Table 2. List of main fishes caught by the set-nets in the Sendai Bay

\begin{tabular}{ll}
\hline & Konoshirus punctatus \\
\hline Konoshiro, Gizzard shad & Scientific name \\
Urumeiwashi, Round herring & Clupea pallasi \\
Nishin, Herring & Sardinops melanosticta \\
Maiwashi, Sardine & Harengula zunasi \\
Sappa & Engraulis japonica \\
Katakuchiwashi, Anchovy & Oncorhynchus keta \\
Sake, Chum salmon & O. masou \\
Masu, Cherry salmon & Plecoglossus alivelis \\
Ayu, Sweet smelt & Tribolodon taczanowskii \\
Maruta, Dace & Anguilla japonica \\
Unagi, Eal & Astroconger myriaster \\
Maanago, Conger & Cololabis saira \\
Sanma, Saury & Hemiramphus sajori \\
Sayori, Half beak & Prognichthys agoo \\
Tobiuwo, Flying fish & Zenopsis nebulosa \\
Kagamidai & Mugil cephalus \\
Bora, Gray mullet & Sphyraena pinguis \\
Akakamasu, Barracuda & Thunnus thynus \\
Maguro, Bluefin tuna & Auxis tapeinsoma \\
Marusoda, Frigate mackerel & Pneumatophorus japonicus \\
Masaba, Mackerel & Trichiurus leptrus \\
Tachiuwo, Hairtail & Coryphaena hippurus \\
Shira, Dolphin & Trachurus japonicus \\
Maaji, Jack mackerel &
\end{tabular}




\begin{tabular}{|c|c|}
\hline Common name & Scientific name \\
\hline Itohikiaji, Threadfish & Alectis cilialis \\
\hline Hiramasa, Yellowtail & Seriola aureovittata \\
\hline Buri, Amberfish & quinqueradiata \\
\hline Kanpachi, Amberjack & purpurascens \\
\hline Sugi, Lemonfish & Rachycentron canadum \\
\hline Medai & Ocycrius japonicus \\
\hline Ishidai, Parrot bass & Oplegnathus fasciatus \\
\hline Ishigakidai & o. $\quad$ punctatus \\
\hline Matsudai, Triple tail & Lobotes surinamensis \\
\hline Mutsu, Japanese bluefish & Scombrops boops \\
\hline Suzuki, Common sea bass & Lateolabrax japonicus \\
\hline Nibe & Nibea mitsukurii \\
\hline Ishimochi, White croaker & Argyrosomus argentatus \\
\hline Kisu, Sillaginoid & Sillago sihama \\
\hline Mejina, Opaleye & Girella punctata \\
\hline Chidai, Crimson sea bream & Evynnis japonica \\
\hline Kurodai, Black sea bream & Mylio macrocephalus \\
\hline Madai, Red sea bream & Chrysophrys major \\
\hline Umitanago, Surf fish & Ditrema temmincki \\
\hline Okitanago, Surf fish & Neoditrma ransonneti \\
\hline Ikanago, Sand lance & Ammodytes personatus \\
\hline Mebaru, Black rock fish & Sebastes inermis \\
\hline Kurosoi & S. $\quad$ schlegeli \\
\hline Takenokomebaru & oblongus \\
\hline Ainame, Greenlings & Hexagrammos otakii \\
\hline Umazurahagi, File fish & Navodon modestus \\
\hline Kawahagi, Trigger fish & Stephanolepsis cirrhifer \\
\hline Kochi, Flathead & Platycephalus indicus \\
\hline Kemushikajika & Hemitripterus villosus \\
\hline Saburo & Occa iburia \\
\hline Hobo, Gurnard & Chelidonichthys kumu \\
\hline Kusauwo & Liparis tanakai \\
\hline Hirame, Bastard halibut & Paralichthys olivaceus \\
\hline Kawagarei, Starry flounder & Platichthys stellatus \\
\hline Ishigarei, Stone flounder & Kareius bicoloratus \\
\hline Magarei, Flat fish & Limanda herzensteini \\
\hline Makogarei, Sole & yokohamae \\
\hline Kuroushinoshita, Tongue sole & Rhinoplagusia japonica \\
\hline Ezoisoainame & Lotella maximowiczi \\
\hline Madara, Cod & Gadus macrocephalus \\
\hline \multirow[t]{4}{*}{ Kianko, Anglerfish } & Lophius litulon \\
\hline & Lamnina \\
\hline & Rajiǹa \\
\hline & Exocoetidae \\
\hline \multicolumn{2}{|l|}{ * Invertebrata } \\
\hline Koika, Cuttlefish & Sepia esculenta \\
\hline Aoriika & Sepioteuthis lessoniana \\
\hline Yariika & Doryteuthis bleekeri \\
\hline Jindoika, Squid & Loligo japonica \\
\hline Surumeika, Sagittated calamary & Todarodes pacificus \\
\hline Saruebi & Trochypenaeus curvirostris \\
\hline
\end{tabular}


the third place $(17.9 \%$ ). In the case of the amberfish, separating the growth stage groups into small sized of 0 year, medium sized of 1-2 years and larger sized of 3 years and upward in age, those compositions are $80 \%, 12.3 \%$ and $7.7 \%$ in the order of their sizes. Accordingly, it can be regarded that the young amberfish in age of 0 year is one of the important fishes among the most influential members from the view point of the coastal fisheries in the Sendai Bay.

Table 3. Annual catch by species and fishing grounds in the Sendai Bay during the period from May to November in 1967

\begin{tabular}{|c|c|c|c|c|c|}
\hline Species name & A & B \& C & $\mathrm{D}$ & $\mathrm{E}$ & Total \\
\hline Engraulis japonica & 9,585 & & 295 & 300,338 & 310,218 \\
\hline Pneumatophorus japonicus & 48,543 & 30 & 1,627 & 239,902 & 290,102 \\
\hline Seriola quinqueradiata (L) & 172 & 12 & 15 & 16,478 & 16,677 \\
\hline$" 1 \quad(\mathrm{M})$ & 17,077 & 470 & 1,596 & 7,447 & 26,590 \\
\hline$"$ & 39,937 & 1,724 & 7,257 & 123,536 & 172,454 \\
\hline Sardinops melanosticta & 157,410 & 3 & 515 & 5,540 & 163,468 \\
\hline Trachurus japonicus & 88,747 & 405 & 2,641 & 269 & 92,062 \\
\hline Auxis tapeinosoma & 9,678 & & 94 & 24,979 & 34,751 \\
\hline Coryphaena hippurus & 110 & & 23 & 33,009 & 33,142 \\
\hline Todarodes pacificus & 2,198 & & 170 & 12,086 & 14,454 \\
\hline Nibea mitsukurii & 12,731 & 716 & 315 & 146 & 13,908 \\
\hline Sphyraena pinguis & 12,543 & & 32 & 370 & 12,945 \\
\hline Lateolabrax japonicus & 497 & 3,090 & 505 & 4,530 & 8,622 \\
\hline Thunnus thynnus & 776 & & & 6,169 & 6,945 \\
\hline Prognichthys agoo & 965 & 13 & 114 & 4,089 & 5,181 \\
\hline Paralichthys olivaceus & 194 & 466 & 12 & 814 & 1,486 \\
\hline Mylio macrocephalus & 451 & 413 & 5 & 590 & 1,459 \\
\hline Seriola aureovittata & 670 & 49 & 8 & 320 & 1,047 \\
\hline
\end{tabular}

In the next place, on the distinctive features of fish faunas in typical areas in the Bay, some descriptions are given from the data of species composition, in the case of 1967.

At the north-east area (E), a distinguishing trait is found in a tendency that gravitation of amounts of catch concentrate towards both the anchovy $(38.5 \%)$ and the mackerel $(30.7 \%$ ) in high level, and that the dolphin (Coryphaena hippurus), the frigate mackerel (Auxis tapeinosoma) and the amberfish show higher rate of appearance as compared with the other areas.

On the other hand, at the south-west area (A), amount of catch of both the sardine (Sardinops melanosticta) and the Jack mackerel (Trachurus japonicus) show high level (39.1$\%$ and $22.1 \%$ ), especially in reference to the abundance of the sardine, it can be seen that this area shows diametrically opposite to the character of the north-east area.

At the area of the mouth part of the Matsushima bay (B-C), it is a prominent characteristics that the common sea bass (Lateolabrax japonicus) show a high amount of catch by far and away. 
Lastly, at the inner part area (D), with the exception of a prominent amount of catch of the young amberfish, there are any distinctive features concerning to the species composition. Looking over the composition of each growth stage of the amberfish, the larger size one appears for the most part in the north-east area, and very rare in the other less than $30 \mathrm{~m}$ in depth.

Researching on the case of warm season in 1969 (Fig. 2), basic property in fish fauna is similar to the case in 1967, though ranking of amount of catch change places to some degrees. Obvious discrepancy in species compositions among the areas in the Bay, suggests the existence of space-time segregation of niche as the result of selection for conditions of life in a field, caused by interspecies correlation connected with adaptational behaviors, such as searching for food and escaping or defensing from enemies.

Considering the background for pelagic fish fauna, it will be reasonable to divide the area of the Bay, basing on species compositions that communicates with partitioning the space for grasp the production structure in the community. From a point of view mentioned above, the coastal area of the Sendai Bay can be divided into four areas; namely, entrance part of the Matsushima bay, the Ishinomaki Bay, south-west area and

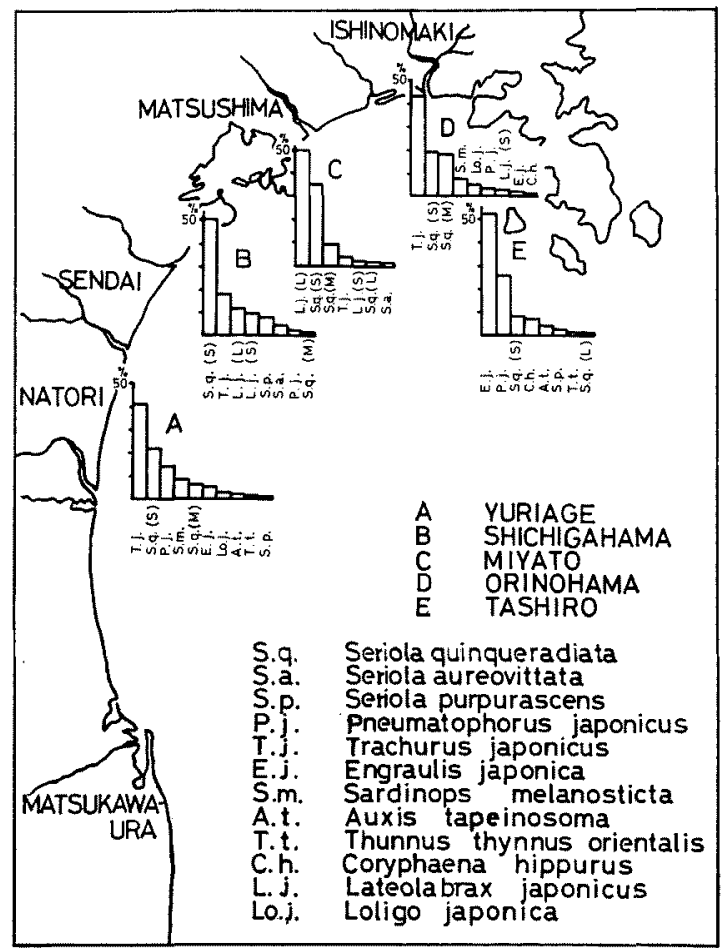

Fig. 2. Species compositions of the fish caught by set nets in the Sendai Bay, from June to August, 1969. 
north-east area of the Sendai Bay.

YАмАмото et al. ${ }^{2}$ have tried to partition the Sendai Bay into three or four biological areas, concerning to the distribution of benthic polychaetous annelids, and also, HATA$\mathrm{NAKA}^{3)}$ has divided water masses of the Bay into four portions, basing on distribution pattern of chlorinity and surface water temperature as shown in Figures 3-a and b. The water mass (area III), raiding into the central part of the Bay from the direction of south-east, divide a coastal area into two parts, north (area I) and west (area II). And he called the rest area of east part of the Bay as the open sea area (area IV). These results may be taken to indicate that there is an apparent parallelism of a basic pattern concerning to a distribution of water mass, of benthic fauna and of pelagic fish fauna. This distributive phenomena suggests that there is close interspecies relationship in each of the growth stages of the fishes adaptationally connected to conditions nonorganic environments. Accordingly, it may be suggested that species composition is not a representation of the result of a random distribution owing to the physical force, but a phenotype of some systematic production structure in ecosystem, in the case arranging by the limitation in space time by means of some suitable methods.

Seasonal transition in fish fauna Since the set-net have generally been set up at near coast, it may be considered that changes of the daily amount of catch reflect the state of movement of fish schools migrate in and out of the Bay, in spite of insufficiency in re-

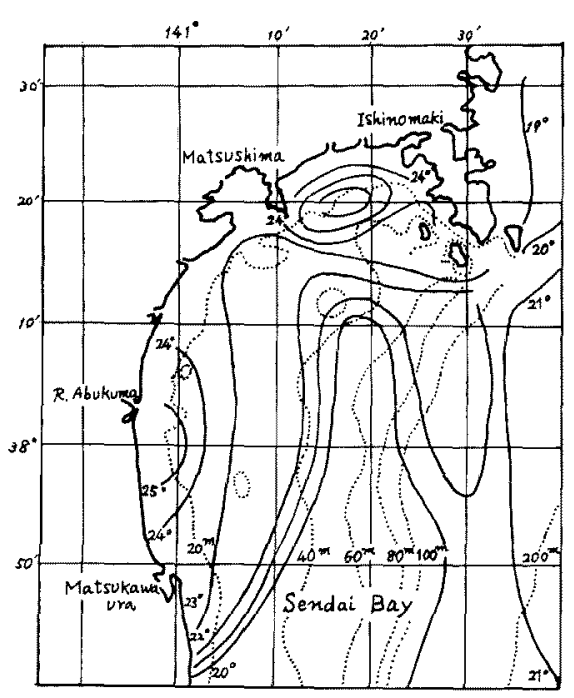

Fig. 3-a

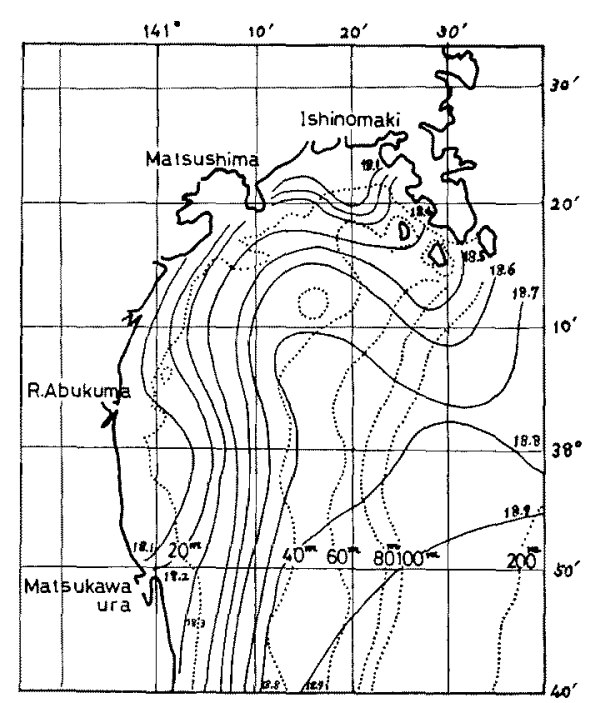

Fig. 3-b

Fig. 3-a. Distribution of surface temperature in July 23-27, 1969, in the Sendai Bay (after Hatanaka, 1971).

Fig. 3-b. Distribution of surface chlorinity in Oct. 28-Nov. 1, 1969, in the Sendai Bay (after Hatanaka, 1971). 
searching for the actual state of the distribution and life of fishes.

In this part, the author has taken a general view of a seasonal transition of amount of catch in each species, based on records of catch in the fishery grounds A, D and E. Figure 4-a, b, c show typical states of the change of amount of catch concerning to the main species during the fishing season of set-nets in the Sendai Bay. The amount of catch has been represented by the rate in per cent of catch in a period of ten days to the total catch.

At the fishery ground of north-east part of the Bay, regions of Tashiro island near the Oshika peninsula, as shown in Figure 4-a, the file fish (Navodon modestus), the angler fish (Lophius litulon), young cherry salmon (Oncorhynchus masou), jouvenile of the cod fish (Gadus macrocephalus), the common sea bass and the gurnard (Lepidotrigla microptera) appear simultaniously in late April, when the surface water temperature ${ }^{4}$ is approximately $10^{\circ} \mathrm{C}$ (Fig. 5). They have been composed a main part in amount of catch up to the ten days of May; showing one peak or two of the amount of catch during the time from May

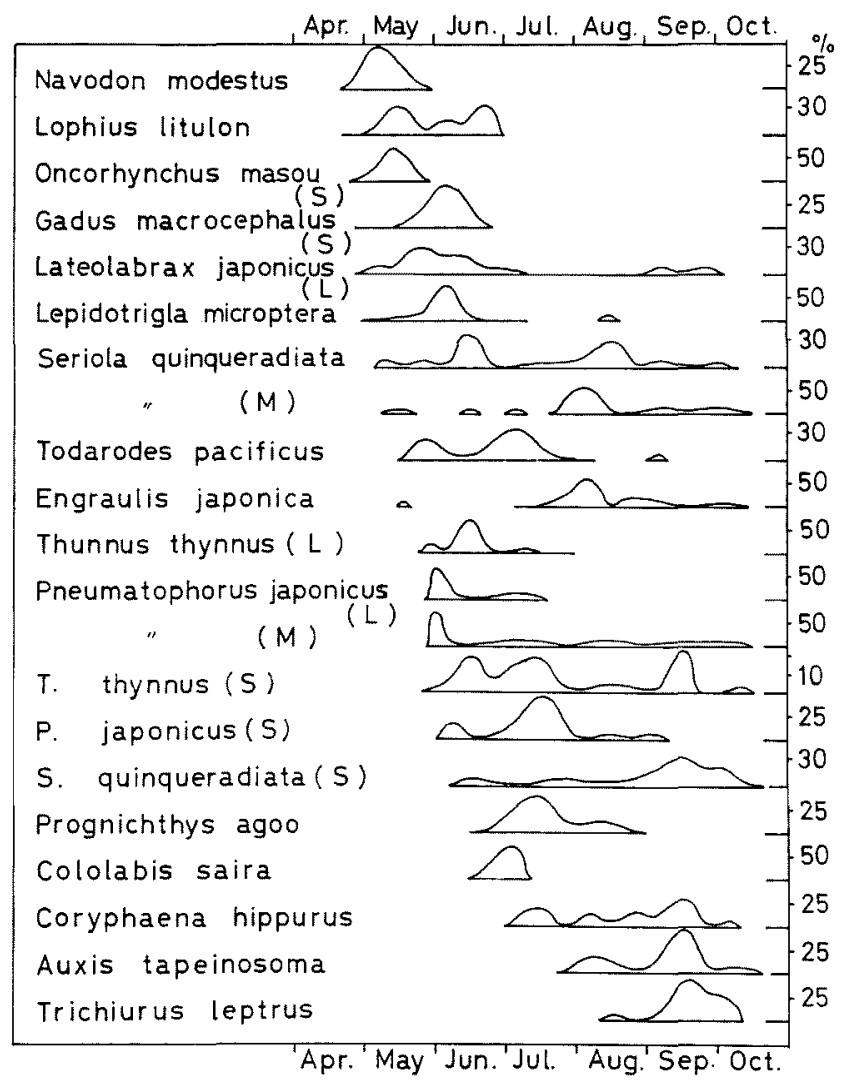

Fig. 4-a. The sequent fluctuations of amount of catch of the coastal fishes caught by the set-net in the fishing area $E$ (Tashiro isl.), 1968. Curves shwoing the ratio of catch in every 10 days to the total amount of catch of each species. 


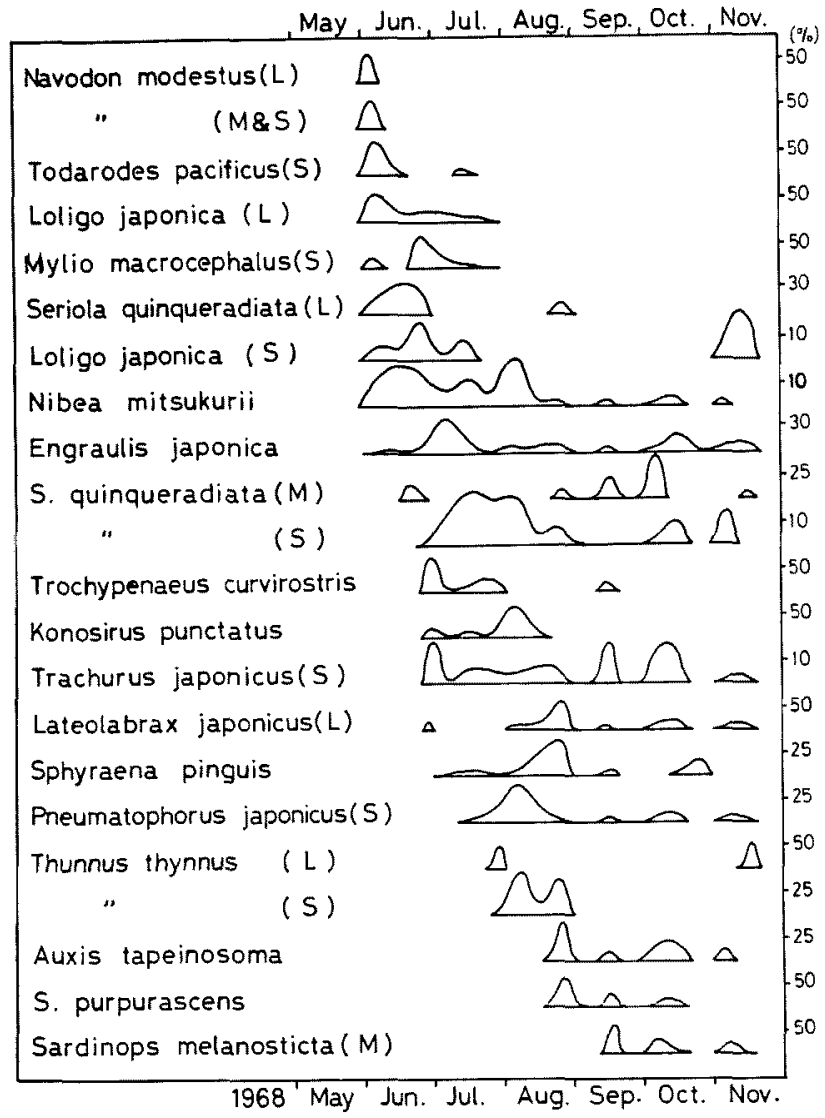

Fig. 4-b. The sequent fluctuations of amount of catch of the coastal fishes caught by the set-net in the fishing area A (Yuriage), 1968. Curves showing the ratio of catch in every 10 days to the total amount of catch of each species.

to June, and the fishes excepting the common sea bass get out of sight at about the beginning of July.

After a while, in the first ten days of May, the large and medium sized amberfish are coming into the area, when the surface water temperature shows approximately $12^{\circ} \mathrm{C}$ as in other years. The large sized has peaks of catch in the second third of June and of August, and the medium sized appear almost continuously up to the middle ten days of October, showing the peak of catch at the beginning of August.

In the second third of May, the sagittated calamary (Todarodes pacificus) and the anchovy are coming in. The former is continuously appearing up to the beginning of August, and the latter continues to the second third of October.

In the last ten days of May, the large and small sized blue fin tuna (Thunnus thynnus) and the large and medium sized mackerel are coming in at the same time, and after that 


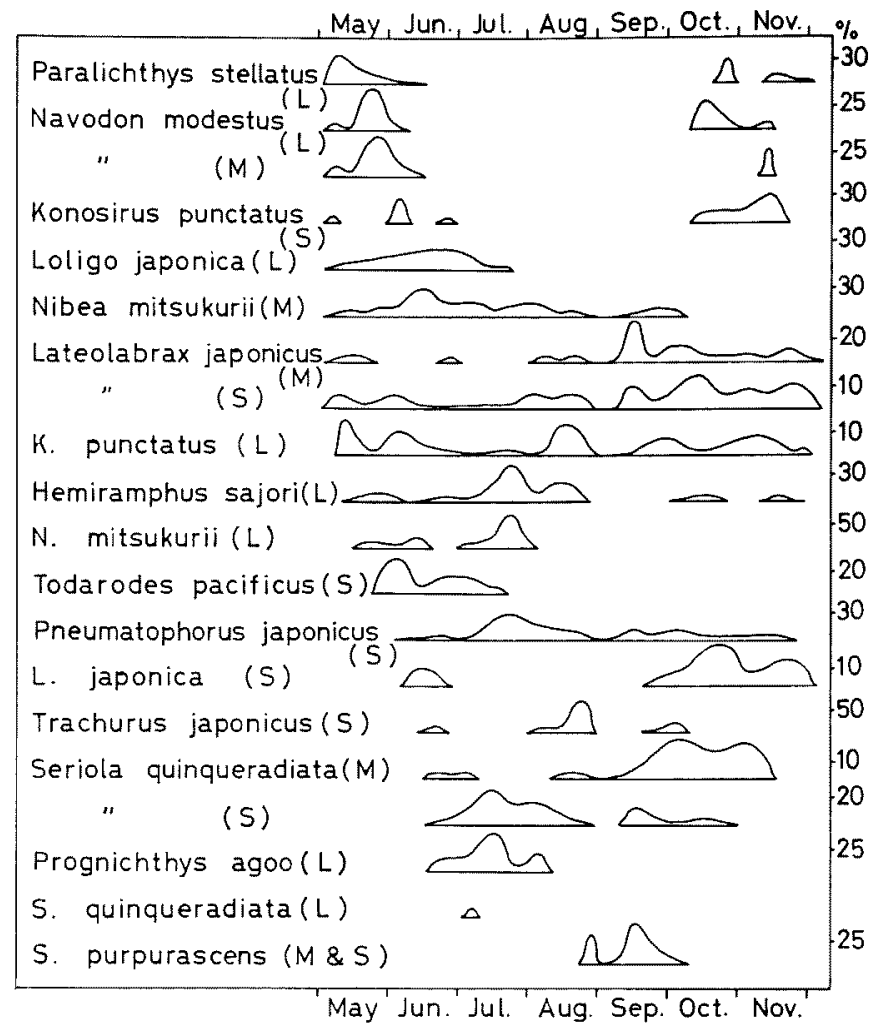

Fig. 4-c. The sequent fluctuations of amount of catch of the coastal fishes caught by the set-net in the fishing area D (Orinohama), 1968. Curves showing the ratio of catch in every 10 days to the total amount of catch of each species.

the small sized mackerel and the small sized amberfish are coming in at the beginning of June. The small sized mackerel has its peaks of catch in the beginning of June and the middle ten days of July, and the small sized amberfish in the middle of June and that of September.

Most of species, as mentioned above, have been appeared up to the middle ten days of August, when the surface water temperature in the Bay has attained to the maximum $\left(25-26^{\circ} \mathrm{C}\right)$ and is going to decline (Fig. 5).

At the fishery ground of south-west part of the Bay, along the coast of Yuriage, as shown in Fig. 4-b, the file fish, the squid, the sagittated calamary, black sea bream (Mylio macrocephalus), the large sized amberfish, the nibe (Nibea mitsukurii) and the anchovy are coming in. The large sized amberfish, showing peaks of catch in June and late in August, has no continuity of appearance such as the case of the north-east area, and the amount of catch is rather small. The nibe and the anchovy are appearing continuously up to the middle ten days of October. 


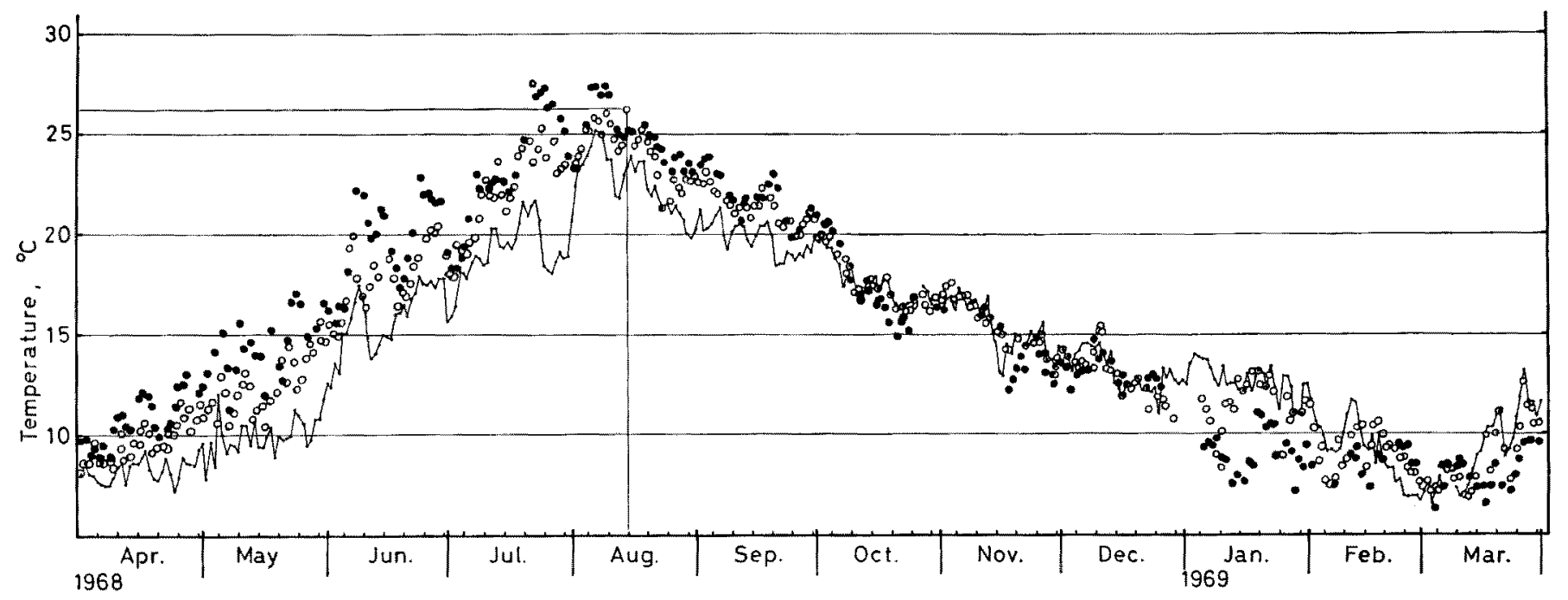

Fig. 5. Seasonal fluctuations of surface water temperature, during the period from April of 1968 to March of 1969, at a coast and the neighbourhood area of the Sendai Bay.

0 , Tashiro island; $\bullet$, Inner part of the Bay; - ..., Enoshima 
The medium sized amberfish is coming in at the middle ten days of June, and the small sized late in the month. In the wake of the amberfish, the shrimps (Trochypenaeus curvirostris), the gizzard shad (Konosirus punctatus), the small sized jack-mackerel, the common sea bass and the barracuda (Sphyraena pinguis) are successively coming in.

Peaks of catch of the small sized amberfish can be seen respectively, during the period from the mid-July to the beginning of August, in mid-October and at the beginning of November. And then, during the period from early in July to mid-August, the small sized mackerel, the blue fin tuna, the frigate mackerel and the kanpachi are successively migrating in; and lastly, in mid-September, the sardine comes in sight, which constitute a characteristic feature of this fishing area in the Bay.

At the fishing ground of the inner part of the Bay (D), first of all, at the beginning of May, the Kawagarei (Platichthys stellatus), the file fish, the gizzard shad, the squid, the nibe, the common sea bass and the half beak (Hemiramphus sajori) are coming in. Among these species, preceding three fishes are out of sight for a time during the period from mid-June to October and are coming again in mid-October and last to November.

Through mid-May into June, the large sized nibe, the sagittated calamary, the small sized mackerel and the squid are coming in the area at intervals of a period of ten days; and in mid-June, the small sized jack mackerel, young amberfish and the flying fish (Cypselurus sp.) are migrating in simultaneously. The amberfish show the maximum values of catch twice during the periods, through mid-July into August and in mid-September, and the staying period continues into late in October.

The large sized amberfish appear during the period from late in June into July, uncommonly in this fishery ground.

Looking through the state of appearance in each species quantitatively concerning to the three fishing grounds in the Bay, as mentioned above, it can be observed that there present some marked differences in the main species composition between three areas each other, and present a time lag pertaining to the first period of appearance and the period of the formation of the maximum catch in each species according to the fishing area. Nevertheless, in a period of temperature rise, many species of fish appear in each area following one another, and most of the main species are already in the areas by middle or late August, when the water temperature begins to show a descending tendency.

As a whole, it can be found that the period of appearance is rather short, in the case such as the file fish migrating in at an earlier period of time, and as the blue fin tuna and the frigate mackerel appearing comparatively behind time. On the other hand, some species such as young amberfish, the anchovy, the mackerel and the jack mackerel, appearing for the middle of the two periods above mentioned, show rather long sojourning period of time. Namely, during the period from late in June to the beginning of July, numbers of species caught by the set-nets show the maximum, and that this is a charac- 
teristic common to the three fishery grounds, each of which has different species composition.

Each species shows peaks of amount of catch one or more times during their staying period surely. From the view of the tendency for peaks, at an interval of a period of ten days, it can be recognized that the peaks in catch at any one time is conposed of not more than five species at the maximum, and generally two or more species populations, linked either with predator-prey relationships, and scarcely overlap with each other in a restricted space.

Assuming the peaks of amount of catch for an index of size of schools migrating in the fishery ground of the Bay, that is a part of whole distributional areas for species populations, it may be suggested that species populations migrate and distribute in their living zone not to overlap preferably with another species populations, and that there aresome stratified constructions in interspecies and distributional relationships in the coastal fish fauna. The phenomena, mentioned above, can be considered fundamentally as a result of interspecies coadaptation, in order to avoid an inordinate competition on getting foods and attacking by enemies, for the sake of preservation and development of the production of the species population.

Interspecies relationships concerning common food items in communities As well as in the amberfish community, we can find many species of fish which prefer the anchovy for food in the coast, as mentioned in the previous paper. ${ }^{13}$

In the area A, during the period July 5 to August 20, by way of example, the predators of anchovy are the kanpachi of $14-24 \mathrm{~cm}$ in fork length, the barracuda of $17-25 \mathrm{~cm}$, the japanese bluefish (Scombrops boops), the nibe of 10-20 cm, the black rockfish of 9-16 cm and the jack mackerel of $13 \mathrm{~cm}$ and over: and, during the period from August 28 to October 29 , the kanpachi of $20-21 \mathrm{~cm}$, the common sea bass of $16-20 \mathrm{~cm}$, the frigate mackerel of 29-31 cm, the nibe of 10-30 cm, the white croaker (Argyrosomus argentatus) of $10-20 \mathrm{~cm}$ and the mackerel of $8-20 \mathrm{~cm}$.

On the basis of the frequency occurrence of food items found in stomachs, food niche of each species relatively to the amberfish has been decided, as shown in Fig. 6 .

Then, taking the case of area A, possibilities for the interspecies competition for food, have been investigated, comparing the seasonal variations of the standing crop in each species.

First, as shown in Fig. 5-b, vast number of small sized amberfish are migrating in and out of the Bay, covering over a period of a month, showing the peak of amount of catch in mid-July. The anchovy appear about 20 days preceding the appearance of the amberfish, and show the peak of catch in the first ten days of July. The kanpachi appear on and after mid-August, having a peak of catch in the last ten days, and the centroid of the population shifts apparently to that of the amberfish and of the main group 
(I)

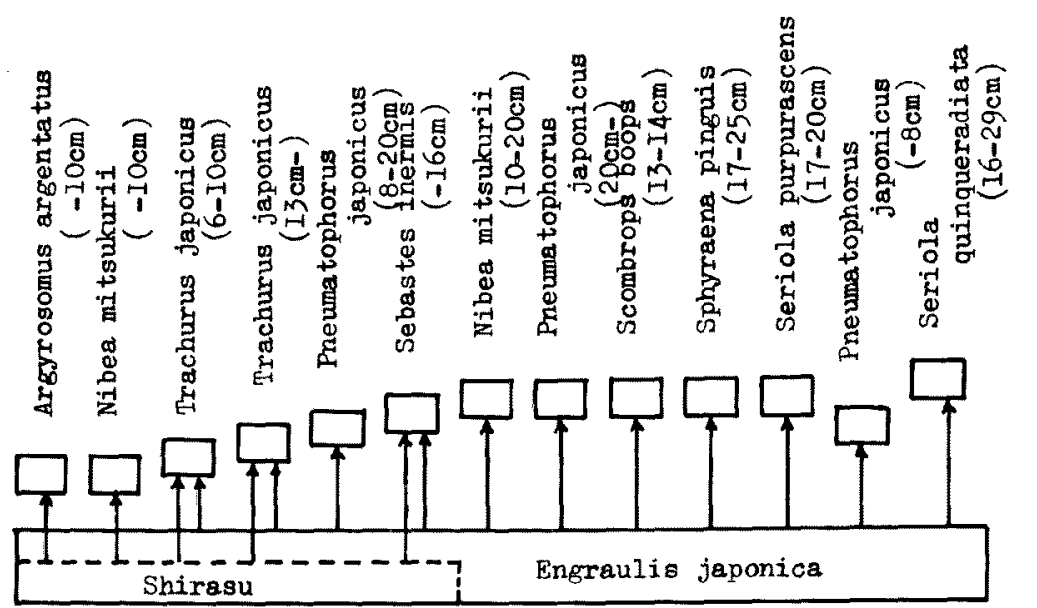

(2)

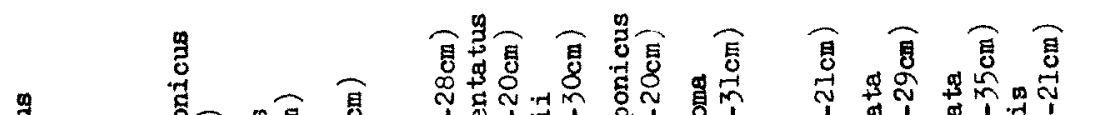

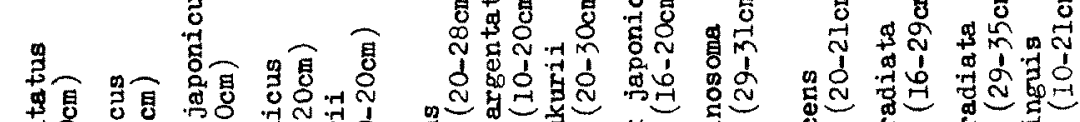

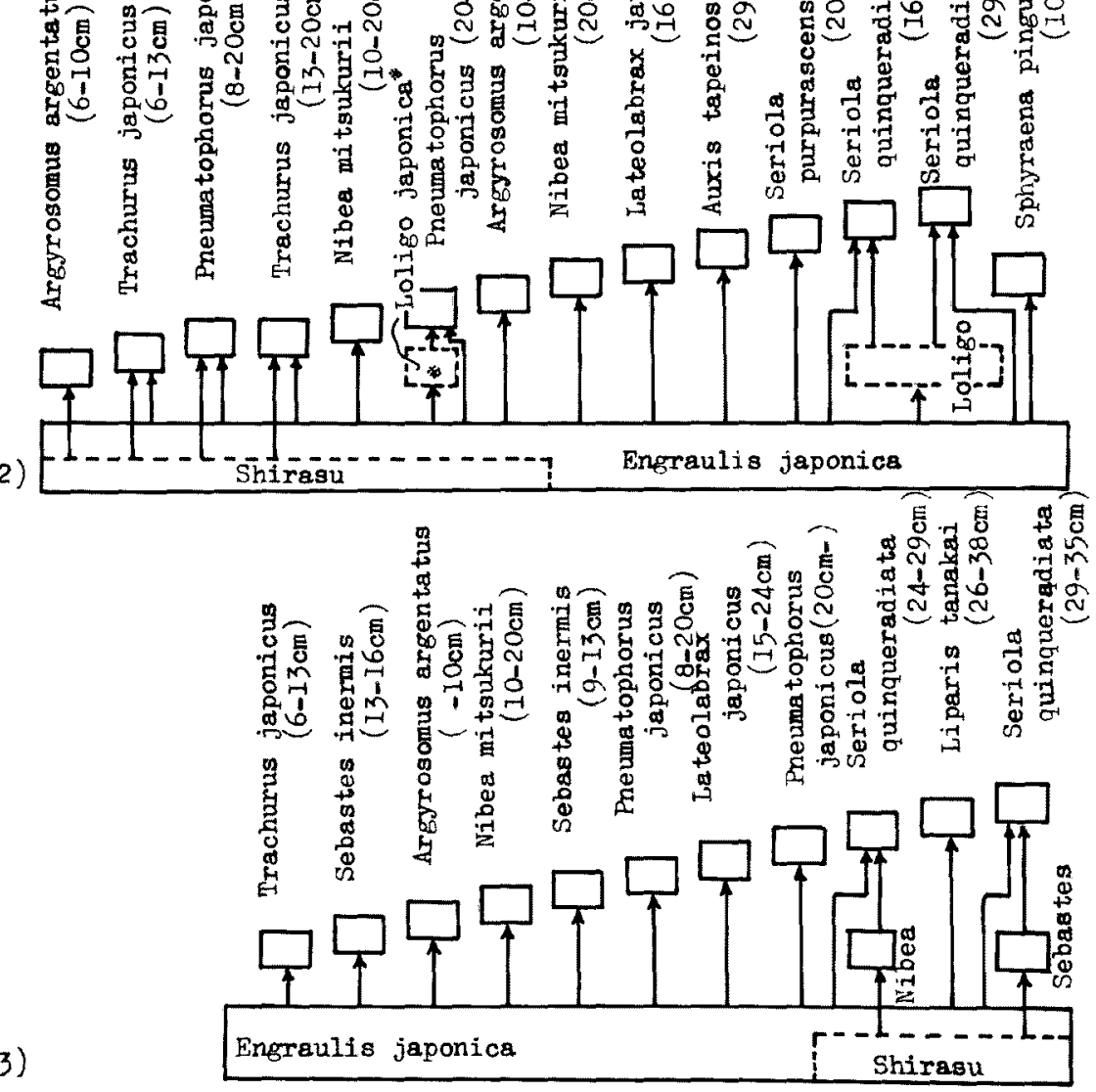

Fig. 6. Relationships on food niche between the young amber-fish and the other fishes feed on the anchovy in the Senday Bay.
(1): Jul. 5-Aug. 20, 1968
(2): Aug. 28-Oct. 29, 1968
(3): Nov. 2-26, 1968 
of the anchovy.

The nibe appear during the period from late in May to the first ten days of November continuously, and the heights of migration are mid-June and the beginning of August, that corresponding to the period just before coming of young amberfish. An appearing period of the mackerel keep up from the beginning of July to mid-November, and the peak of catch gets out of the place for the height of the amberfish, notwithstanding the population exceed to that of the amberfish.

On the other hand, making a conjecture from the amounts of catch, populations of the barracuda and the Japanese bluefish are approximately $3.4 \%$ and $1 \%$ of the amberfish. Namely, the level of the competition concerning to the food item may be considered in a low grade, in relationships between any and every species to the young amberfish.

During the period from August 8 to October 29, the small sized amberfish show a peak of catch at mid-October, just when a large school of the anchovy are migrating in the area at least 1.8 times of the amberfish in amount of catch, and overlap the peak of catch each other. During the same period, the mackerel show a peak, but the level of the population is rather low, grading about $1 / 2$ of the amberfish. On the other hand, some fishes such as the kanpachi, the frigate mackerel, the barracuda, the nibe and the like are in low level.

On the first ten days of November, the small sized amberfish show a peak, and a large school of the sardine are migrating in. The amberfish eat on the anchovy principally, and show a low degree of dependence on the sardine. Accordingly, amounts of catch of the most species that eat on the anchovy for food are generally rather small, in the case of migrating into the area in company with the amberfish. Even if several species show the appearance of living in the same area seemingly, it is general inclination in fish communities that species taking a common food items distribute evidently, lest they should overlap the center of population each other.

As we have seen, numerous fishes live on the anchovy and the shirasu for food in the coast of the Sendai Bay, for that reason, we can not afford to overlook the fact that the anchovy playing an important role in food sources for carnivorous fishes. Namely, it is reasonable to consider the existence of several communities, the construction fairly independent to the other, like the amberfish community including the anchovy as a key species and maintain a stable organization. However, the formation mechanism of the community is not always identical to that of the amberfish community.

Picking up typical terminal species from fish fauna in the Sendai Bay, the types of community formation can be classified into the following three classes.

The first, waiting type, represented by the common seabass, which appear all the year round, taking the anchovy for food during the period appearing in the Bay and getting away from the living area of the young amberfish.

The second, sojourning type, represented by young mackerel and young jack mackerel, 
having an intense migratory character but sojourning in the Bay for a good while. The fishes are relying intensely on the anchovy or the shirasu for food, and under certain circumstances pertaining to the growth stage, they are often included in the member of the amberfish community and transfer to the another communities.

The third, passing type, represented by the frigate mackerel, the barracuda, the kanpachi, the blue fin tuna and the dolphin, migrating in temporarily during some short period in warm season and feeding intensely on the anchovy, and the peak of migration accord with that of the anchovy.

These three types of communities have the common feature in a point that they include the anchovy as a principal member in a community. However, it is reasonable to consider the main part of the community as separate from other communities in time and space, and that two or more communities rarely hold a common school of the same anchovy population, but connect some definite school of the fish. This is closely related to the unequal quality in career of the anchovy population ${ }^{5)}$ and differences in life habit of the anchovy eaters.

\section{Acknowledgement}

Grateful acknowledgement is made to Professor Emeritus M. HatanaKa, Tohoku University, for suggesting this problem and for stimulating interest in it, and for constant guidance in the course of the work. The author wishes to express heartful thanks to Dr. R. Sato and Dr. S. Nishizawa, Tohoku University, for many valuable suggestions. Thanks are also due to various members of the laboratory staff of Department of Fisheries, Faculty of Agriculture, Tohoku University, and the author has also benefited from the advices and criticisms of members of a research group for JIBP-PM in the Sendai Bay. In preparing this presentation, the author is indebted to Mr. T. WaTANABE, Chief Scientist of Fisheries Experimental Station of Ibaraki Prefecture, for helpful suggestions and observation and a critical reading of the manuscript. Records of daily amount of catch by the set-nets were kindly offered by Mr. S. OKawA, Mr. I. KameYAMA and the Fisheries Association of Tashiro island in Miyagi Prefecture.

This work was supported financially in part by a Grant in Aid for Fundamental Scientific Research of the Ministry of Education.

\section{References}

1) A. OKata: This Bull, 41, 1247-1262 (1975).

2) G. Yamamoto, R. Kitamori, M. Nishihira, I. Shishido, N. Yokoyama, and T. Habe; Interim Report of the Studies on the Sendai Bay for JIBP/PM, No. 2, 109-119 (1969).

3) M. Hatanaka: ibid., No. 4, 77-84 (1971).

4) Fisheries Experimental Station of Miyagi Prefecture: ibid., No. 2, 13-52 (1969).

5) A. Okata, H. Abe, K. Uchino, H. Hanabuchi, Y. Chida, and M. Hatanaka: ibid., No. 5, 79-106 (1972). 